\title{
El amor fillial como acción colectiva y confianza
}

\section{Adrián Scribano*}

\section{Resumen}

Vivimos en sociedades normalizadas en el disfrute inmediato a través del consumo, que configuran una economía política de la moral atravesada por la banalización del bien, la lógica del desecho y la política de la perversión. Esta estructura es desmentida cotidianamente por prácticas intersticiales, entre las cuales el amor filial es una las más relevantes. El artículo pretende sintetizar los resultados de una etnografía digital realizada en México, Guatemala, Brasil, Uruguay, Chile y Argentina, con relación a las articulaciones entre el amor filial como acción colectiva y los lazos de confianza que dichas prácticas generan. El amor filial en tanto práctica intersticial produce interacciones de reciprocidad y confianza entre a) los actores y personas que participan, $b$ ) otras prácticas colectivas y c) "espacios institucionales". Desde las prácticas de amor filial aparece la confianza y esto produce un conjunto de prácticas del sentir que se mueven en una dialéctica entre dolor y encuentro que cualifica las inversiones emocionales que las personas vivencian. El presente trabajo apunta a mostrar cómo el amor filial en tanto acción colectiva desmiente el régimen de verdad de la actual economía política de la moral, enfatizando el lugar de la confianza en dichas prácticas colectivas. Para lograr dicho objetivo, se ha elaborado la siguiente estrategia expositiva: a) se sintetiza lo que se entiende por prácticas intersticiales y amor filial, b) se presentan las seis experiencias seleccionadas у с) se consigna una breve conclusión.

Palabras Claves: amor filial, confianza, acción colectiva, dolor, encuentro.

*Universidad de Buenos Aires, Buenos Aires, Argentina. 


\section{Filial love as collective action and trust}

\section{Abstract}

We live in societies normalized around immediate enjoyment through consumption, which constitutes a political economy of morality permeated by the trivialization of good, by the logic of waste and the politics of perversion. This structure, however, is denied every day by interstitial practices, among which the filial love is one of the most relevant. This article aims to synthesize the results of a digital ethnography carried out in Mexico, Guatemala, Brazil, Uruguay, Chile and Argentina in relation to the links between filial love as collective action and the bonds of trust generated by these practices. Filial love as an interstitial practice produces interactions of reciprocity and trust a) between the actors and people involved, b) with other collective practices and c) with "institutional spaces". From the practices of filial love, trust emerges, producing a set of feeling practices that move dialectically between pain and encounter thus qualifying the emotional investments that people experience. The present work aims to show how filial love as collective action denies the regime of truth of the current political economy of morality, emphasizing the place of trust in such collective practices. To this end, the work is structured according to the following explanatory strategy: a) what is understood by interstitial practices and filial love is synthesized, b) the six selected experiences are discussed and c) a brief "conclusion" is proposed.

Keywords: filial love, trust, collective action, pain, encounter.

\section{Introducción}

I presente trabajo apunta a mostrar cómo el amor filial en tanto acción
colectiva desmiente el régimen de verdad de la actual economía
política de la moral, enfatizando el lugar de la confianza en dichas
prácticas colectivas. Para comenzar, se sintetiza un diagnostico posible
de la situación actual que, sostenemos, tiene una escala planetaria y una
profundidad local estratégica para el presente proceso de expansión del
capitalismo.


La situación actual del capitalismo ${ }^{1}$ a escala planetaria, y enfáticamente en el Sur Global, se caracteriza por: la existencia de una gran máquina depredatoria de agua, aire, tierra y, en especial, energía corporal; el diseño y gestión de los mecanismos de soportabilidad social y dispositivos de regulación de las sensaciones entramados en y a través de fantasmas y fantasías sociales; y un aparato global de represión, no sólo la militar/ policial sino también, y fundamentalmente, la operada en la vida cotidiana - racializaciones, femicidios, expulsiones masivas etc.

En este marco, en nuestras investigaciones, hemos constatado la concreción de lo que hemos dado en llamar religión neo-colonial (Scribano, 2013b; 2014). Esta amalgama al consumo mimético, la resignación y el solidarismo como dogmas que explican y "dan sentido" a una economía política de la moral que socializa unas pastorales en términos de una "sociodicea de la frustración", que se expresa en tanto apraxia, ataxia y sinestesia.

Así, hoy vivimos en sociedades normalizadas en el disfrute inmediato a través del consumo. Asistimos a una re-estructuración permanente de la economía política de la moral ${ }^{2}$ a través del aludido disfrute. El eje de las políticas económicas de muchos de los estados del Sur Global es su carácter "neo-keynesiano", por lo cual los incentivos "oficiales" para el consumo se cruzan y superponen con el estado consolidado y en continuo desarrollo del capitalismo en su contradicción depredación/consumo. Así, se producen/reproducen unas sociedades estructuradas en torno a un conjunto de sensibilidades cuyo contexto de elaboración lo constituyen los continuos esfuerzos por seguir consumiendo (Scribano, 2015a; 2015b).

Este artículo busca mostrar algunos avances de una investigación sobre el amor filial en tanto acción colectiva, que venimos realizando en seis países gracias a la colaboración de jóvenes colegas que nos han brindado su desinteresado apoyo: Melina Amao Ceniceros (México), Jeanie Herrera

${ }^{1}$ Nuestra mirada sobre matriz conflictual, diagnóstico del sur global, acciones colectivas ha sido extensamente expuesto en los últimos 20 años, para no ocupar lugar solo con citas autorreferenciales, citamos aquí una síntesis en Scribano (2017).

${ }^{2}$ Sobre cómo se comprende la relación entre economía política de la moral y estructuración de las sociedades capitalistas, ver Scribano (2013a; 2013b; 2015b). 
(Guatemala), Joziene Assis (Brasil), Sharon Díaz (Uruguay) y Rafael Ariaza Peña (Chile).

La estrategia metodológica consistió en desarrollar una etnografía digital $^{3}$ basada en: a) la elaboración de tres tipos de registros: notas de campo virtuales, selección y análisis de momentos relevantes en la vida de los colectivos, y descripción de contenido y análisis de documentos disponibles en la Web; estas fueron útiles para reconstruir las particularidades y diferencias en cada uno de los componentes de las páginas web y las noticias de las redes sociales sobre los colectivos investigados; y b) la etnografía digital, llevada a cabo en siete países de América Latina: México, Guatemala, Brasil, Uruguay, Chile y Argentina. La investigación abarca un numeroso grupo de prácticas colectivas (más de 100) que tienen o han tenido presencia en Internet y cuya experiencia social se haya instalado desde la década de 1970 hasta la actualidad. Los registros se realizaron en dos tipos diferentes de tablas donde se sistematizaron por década/año de creación del colectivo, descripción de la práctica, logotipo/imagen/dibujo utilizado como identidad social, miembros y años.

\section{Prácticas intersticiales y amor filial}

Desde hace tiempo estamos indagando sistemáticamente las consecuencias y efectos prácticos de lo que, para nosotros, constituye un diagnostico básico y orgánico del estado actual de la estructuración del capitalismo en el Sur Global.

En dichas pesquisas hemos encontrado, descripto y analizado lo que hemos Ilamado la configuración de una "religión neo-colonial", cuyos ejes centrales se constituyen (en y) a través del consumo mimético, el solidarismo y la resignación. Como resultado de las observaciones realizadas, hemos relevado, entre otras, un conjunto de prácticas performadas por los sujetos, de las cuales, en pocas ocasiones, las investigaciones sociales dan cuenta: la felicidad, el intercambio recíproco y el amor.

${ }^{3}$ Como es ampliamente conocido, una etnografía digital y/o virtual no consiste en "meras lecturas de páginas web". Ver De Sena y Lisdero (2015), Mosquera (2008), Pink et al. (2016) y Skågeby (2010). 
Las prácticas que hemos analizado fueron inscriptas en una red teórica y epistémica que involucra cruces y entramados entre algunas de las miradas sobre las acciones colectivas y el conflicto, la sociología de las emociones y de los cuerpos y la crítica ideológica. Básicamente, el esquema que ha guiado nuestras investigaciones es el siguiente: existen, en la "vida de todos los días" de los millones de sujetos expulsados y desechados de Latinoamérica, pliegues in-advertidos, intersticiales y ocluidos. Se efectivizan, así, prácticas de la vida vivida en tanto potencia de las energías excedentes a la depredación. En este contexto, aparecen en el horizonte de comprensión prácticas para las cuales la sociología no tiene - usualmente - un plexo crítico, conceptual y metodológico demasiado elaborado. Algunas de las prácticas aludidas son la felicidad, la esperanza y el disfrute, que emergen como contracara de los ejes de la religión neo-colonial enunciada.

En este marco, las prácticas intersticiales son aquellas relaciones sociales que se apropian de los espacios abiertos e indeterminados de la estructura capitalista, generando un eje "conductual" que se ubica transversalmente respecto a los vectores centrales que configuran las políticas de los cuerpos y las emociones (Scribano, 2017). Por lo tanto, no son prácticas orto-doxas, ni para-dóxicas o hetero-doxas, en el sentido conceptual que les diera a estas Pierre Bourdieu. Entre las muchas maneras de entender conceptualmente qué significan las prácticas aludidas, mencionaremos tres de ellas: como pliegues, quiebres y partes "no esperadas" de un puzzle.

Las prácticas intersticiales anidan en los pliegues inadvertidos de la superficie naturalizada y naturalizante de las políticas de los cuerpos y las emociones que supone la religión neo-colonial. Estas prácticas se actualizan e instancian en los intersticios, entendiendo a estos como los quiebres estructurales por donde se visibilizan las ausencias de un sistema de relaciones sociales determinado. Estos quiebres son espacios irregulares donde los sujetos construyen un conjunto de relaciones tendientes a soldar la estructura conflictual, pero con estaños diferentes y múltiples. Las prácticas intersticiales son partes "no esperadas" que aparecen asociadas, pero no son parte del puzzle en el que convergen el consumo mimético, el solidarismo y la resignación. 
Estas prácticas se constituyen en tensión con un conjunto de matrices de conflicto, las cuales son modalidades estructurales provenientes de redes conflictuales diversas que les dan origen desde lo que implican las disputas iterativas sobre un bien (sean estos objetos, procesos y/o identidades). Como se verá más adelante, la construcción de esas matrices se opera desde la información obtenida en la indagación etnográfica y, en los casos que aquí referimos, implican la institucionalidad, la violencia social y la impunidad.

\section{Prácticas del querer}

En este marco, comprendemos al amor como un estado afectivo que conecta la relación yo-tú-otro transformando a la misma en una preferencia primera, en objeto de deseo y en meta principal. Esto implica que en esa relación yo-tú-otro se condensan los cortes que hay en la dominación entre necesidad y reproducción. Es decir, la "materialidad" como tal, como base de la estructura de lo cotidiano; de lo que están hechos los cuerpos, de esa capacidad energética de (re)construirse - desde lo genético hasta lo discursivo - pone a la relación yo-tú-otro como preferencia frente la necesidad.

El amor es un pliegue que disputa la resignación en tanto convierte a la relación yo-tú-otro en objeto de deseo. Nuestra mirada aquí se funda en el enfoque sociológico de W. I Thomas sobre el deseo como estructurador de las relaciones sociales. Cuando la relación yo-tú-otro está inscripta en la "energía" del deseo, lo que aparece es la lógica del reconocimiento; como un deseo estructurante, como una acción de querer ser reconocido. Ese deseo de ser reconocido es parte de una lógica que tiene que ver con la reproducción de sí mismo y la reproducción de su entorno. La clave del reconocimiento como resultado de la energía del deseo es la potencialidad que se origina en la ruptura con el abandono. La sociodicea de la frustración implica la impotencia como rasgo de lo social; el amor como práctica intersticial involucra la energía de saberse con otro en el mundo en tanto trampolín para la acción.

El amor filial proviene de los lazos familiares e involucra vínculos multidireccionales - padres a hijos, hijos a padres, hermanos a hermanos - y estos lazos complejos proporcionan el lugar central desde el cual aparece la 
energía especial para construir prácticas colectivas. De esta manera, el grupo de prácticas que llamamos amor filial es la consecuencia de un conjunto de relaciones que emergen de la dialéctica de "philial" (con significados de amistad, relaciones familiares cercanas y solidaridad humana) y "storge" (un término más literario para amor familiar o afecto de los padres).

Así, entendemos al amor filial como una práctica intersticial que "se mueve" hacia una práctica colectiva, en conexión con lo que Goffman llama "giro" en las experiencias dramatúrgicas de vida. ${ }^{4}$ En esta línea, Yves Winkin, en su estudio introductorio Momentos: Erving Goffman y sus hombres (1991), sostiene que el amor es uno de los eventos utilizados por Goffman para ejemplificar su concepto de "punto de inflexión": "el amor interviene en un momento de crisis de la gente y 'redirige' toda su conducta $[. .$.$] la reorientación al que el amor conduce puede ser llamada$ 'giro'" (Winkin, 1991, p. 45).

La mayoría de las madres, padres, esposas, parientes y amigos a quienes nos referimos en este trabajo expresan que sus situaciones de pérdida "han cambiado sus vidas": sus interacciones cotidianas, sus héxeis corporales, las formas materiales de reproducir su existencia, en algunos casos, radicalmente. Las situaciones de "pérdida" se disponen de diversas maneras: el perder a la persona querida y el cariño que ella nos dispensaba, la pérdida de miedo ante la situación de injusticia/indignidad que implica dicha pérdida y pérdida de sentido de la vida de todos los días organizada en torno a las sensibilidades con otros. En este contexto, es posible advertir cómo una ausencia deviene presencia y energía.

El amor filial es un excedente de energía que se manifiesta como resultado de las tensiones entre las características instituidas de la familia: la legitimidad del tráfico desigual de géneros, la reproducción de la propiedad privada, el proceso de introducción de los componentes básicos de la economía política de la moral y la reproducción material de los cuerpos/ emociones.

Lo intersticial de la energía filial lleva, en sus acciones "imprevistas", el poder de negar la totalización de los contenidos hipostasiados que representan la familia como una institucionalidad desgarrada. Las prácticas

4Para otras miradas sobre "turning point", ver Kálmán (2016) y Turabian (2016). 
colectivas analizadas aquí señalan claramente las distancias que, día tras día, imponen la impunidad, la inmovilización y la expulsión que tienen su negación en los espacios intersticiales del amor. De este modo, el amor filial, conyugal y cívico configuran un reservorio de energías corporales y sociales que activan las especificaciones de las continuidades y discontinuidades que dan lugar a la confianza y confiabilidad que implica la presencia intersticial de la esperanza. Son bandas de moebius que, al dar la vuelta, abren y despliegan las numerosas tiras de un futuro descolonizado de la mercantilización de lo familiar.

\section{Amor filial}

El amor filial, tal como lo entendemos en la investigación que da origen al presente trabajo, puede ser comprendido mejor si se señalan las tramas de dicho concepto que surgen desde una mirada pluridisciplinar (filosofía, antropología, psicología etc.). El amor filial es una modalidad de vinculación como estado emocional que puede ser entendido desde la relación padres-hijos.

Usaremos el término vinculación para referirnos al vínculo entre padres e hijos. La vinculación de los padres incluye componentes mentales y de comportamiento [...] el núcleo de la vinculación es un estado emocional (es decir, "amor") que se relaciona con un conjunto de necesidades o disposiciones, incluido el saber, estar con, evitar la separación y la pérdida, proteger, y gratificantes necesidades del niño. Estas necesidades y disposiciones de los padres pueden, a su vez, provocar la expresión de conductas dirigidas por los niños (De Cock et al., 2015, p. 125 - traducción propia).

Retomando la sociología clásica, Elena Pulcini sostiene, siguiendo a Simmel, que el amor debe ser comprendido como la síntesis de tres dimensiones ágape, eros y philia (Pulcini 2017). Mounier ha descripto la comunalidad que implica el amor y las implicancias que ello tiene sobre la constitución de las personas: "Esta comunión de amor, al liberar al que responde, también libera y tranquiliza a quien lo ofrece" (Mounier, 1962, p. 23 - traducción propia). "Yo amo, luego soy" se propone como una huella nodal para comprender cómo la energía del amor filial impulsa lo 
colectivo y reconstruye identidades. Es la tensión existencial del dolor en la vida y de los riesgos que ello implica.

Levinas, en su libro Totality and infinity. an essay on exteriority, (1979) se aproxima a una mirada del amor como preocupación por el otro, que se articula estrechamente con la modalidad del amor filial, tal como la estamos describiendo. El amor se orienta hacia el otro procurando asistirlo en esa cualidad tan humana como es la fragilidad, rasgo que demanda e interpela a los otros y al "yo" respecto a esos "otros" (Levinas, 1979).

En una línea similar, en la siguiente afirmación de Gabriel Marcel (1949) sobre las conexiones entre deseo, amor, tener y ser, encontramos pistas más que interesantes para pensar la energía del amor filial. En primer lugar, la energía del amor filial es un "estar-siendo", transciende ese serestar con esta capacidad de estar ocurriendo como rasgo de su presencia. En segundo lugar, es un más acá del tener, dado que no es posesivo. Y, en tercer lugar, el amor filial es un "entre"; adviene "en-un-medio" del yo-tú.

De esta forma, el amor filial destituye la sacralidad del miedo a las consecuencias del riesgo como mecanismo de resignación a una vida sin autonomía. En lo que sigue, veremos cómo el amor filial deviene práctica colectiva y en ello desmiente el régimen de verdad de una política de la sensibilidad anclada en el miedo y en la resignación.

\section{Amor filial y confianza: seis experiencias en Latinoamérica}

La confianza se estructura en torno a tres factores claves: creer, tomar riesgos, dar por sentado/estar-seguros-que. Hay dos maneras de entender el lugar del creer en la generación de la confianza: el creer en el otro y el creer con el otro. Creer es una acción cognitivo-afectiva en la existencia de coherencia entre lo que se supone/espera y los resultados de la acción de otro y/u otros. Las personas que participan en las prácticas intersticiales analizadas relatan y performan una recuperación de la posibilidad/capacidad de creer en sus pares al encontrar otros en su misma situación. También se cree con otros y/u otros, dado que, por definición, la creencia es una práctica compartida que deviene sociabilidad y vivencialidad común. Las personas que participan en acciones basadas en la energía del amor filial crean un horizonte de comprensión común que implica un diagnóstico y 
una prognosis colectivamente aceptados. El creer en los otros y con los otros elabora una especial política de la sensibilidad que disputa el monopolio de la verdad a la economía política de la moral.

La generación de confianza se elabora directamente a través de "tomar el riesgo" de esperar coherencia y reciprocidad de las otras personas. Las personas hacen una apuesta respecto al cumplimiento de la palabra, las intenciones del otro y el compromiso con la problemática que los reúne. Los seres humanos aprendemos a equilibrar riesgo y fiabilidad como una modalidad de gestión de lo cotidiano. En las prácticas colectivas que analizamos es fundamental la redefinición de estas relaciones entre el "no saber" y de todos modos "esperar que pase". Por otro lado, confiar en alguien o en algún sistema experto implica el dar por sentado que los estados de cosas suelen repetirse. Las personas creen porque descuentan que alguien o algún mecanismo actuará en tanto se espera que lo haga; para vivir las personas "primero" dan por segura la reproducción de la vida tal como la conocen: es decir confían. La ruptura de dicha confianza es la raíz, pero también el síntoma de las crisis sociales. Es en este contexto que las prácticas del querer conectadas con el amor filial despiertan, reconstruyen y elaboran relaciones sociales basadas en la confianza, más acá de su negación enclavada en la economía política de la moral.

En esa misma línea, la confianza se presenta como una posibilidad de estabilización de expectativas: en tanto fiabilidad en la política de los sentidos, como seguridad en los sistemas expertos y en cuanto previsibilidad de los errores. El oler, tocar, gustar, oír y ver permiten conocer el mundo y esas prácticas posibilitan confiar en su iteratividad. Pero también, como ya se anticipó, las prácticas del confiar se basan en la aceptación de la eficiencia de los sistemas expertos que manejan el mundo como intermediarios entre lo humano y el mundo externo.

La confianza es una práctica del sentir que opera al nivel de las expectativas, es una modalidad de gestión del umbral de monitoreo reflexivo de la acción y la experiencia de compartir un horizonte de percepción. Los seres humanos esperamos de los otros ciertos tipos de comportamientos asociados a la proximidad/distancia de las variaciones de las prácticas regularmente instanciadas en situación de interacción. Confiamos cuando 
esperamos que la otra persona actúe de acuerdo con lo que de ella se espera. Confiar en tanto expectativas regulares es una forma de disminución de la incertidumbre del futuro.

La confianza se vuelve una práctica del sentir cuando una persona deja de experimentar la necesidad de monitorear su acción frente a otra u otras personas; es un "descanso" del estado de alerta, es una actitud "relajada" frente a lo que pueda ocurrir. Confiamos cuando aumentan nuestras certezas sobre lo innecesario de "controlar" la situación. En otro sentido, confiar y confianza se conectan directamente con las evidencias de compartir horizontes de percepción con una persona o grupo de personas. El mundo es percibido en y a través del cuerpo y esto implica una relación entre cuerpo piel, cuerpo imagen y cuerpo movimiento - cuando las personas constatan que comparten alguna forma específica de la relación aludida con otra persona confían en ella. La confianza se trama con el amor filial de modo tal que posibilita desmentir un régimen de verdad que se presenta como totalidad cerrada en los procesos de estructuración de sociedades cerradas en el consumo autocentrado.

Inscripto en el contexto aludido, revisemos ahora seis experiencias de amor filial y su conexión con la confianza ${ }^{5}$.

\section{Mães em luto da Zona Leste (Brasil)}

Brasil, desde hace muchos años, se encuentra sumergido en una nueva fase de lo que se Ilamó, en los años 1960, espiral de violencia (Câmara, 1971). En aquellos años, se la describía de la siguiente manera: a la naturalización de la violencia cotidiana del hambre y la pobreza, le sigue un proceso helicoidal de protesta, represión, más violencia institucional, aumento de respuesta y protesta, más represión. En los primeros 19 años

\footnotetext{
${ }^{5}$ Las experiencias aquí presentadas se han seleccionado teniendo en cuenta su "representatividad" para conectar matriz de conflicto, emociones y confianza bajo el supuesto que, como se entiende aquí, una etnografía digital es un procedimiento que permite comprender las prácticas de los sujetos desde sus mismas miradas. Las prácticas digitales tienen en sí mismas la especial articulación entre elaboración, régimen escópico y visualización conflictual. Parafraseando una conocida frase sobre la política, del expresidente Clinton, "Son las emociones, iiestúpido!!" las que los participantes mismo gestionan, elaboran y reproducen en estas experiencias "virtuales".
} 
del siglo 21, como en casi toda América Latina, se han mantenido y hecho más reticulares los procesos de "represión preventiva", etiquetamiento, segregación racializante y naturalización de la muerte.

Según el Fórum Brasileiro de Segurança Pública ${ }^{6}$, en 2017 ha habido 63.895 muertes violentas intencionales, 175 muertos por día, lo que implica una tasa del 30,8 por 100 mil habitantes. También se pueden constatar 82.684 desaparecidos, 61.032 estupros, 1.133 femicidios y 221.238 casos de violencia doméstica. Hasta la fecha se ha experimentado el espiral más armas, más represión, más armas, naturalización de la violencia. Un eje central de este proceso es la militarización de la policía y el policiamiento de las fuerzas armadas.

En este contexto nacen "Mães em Luto da Zona Leste" que, en su Facebook, enuncian: "[...] Esta página fala sobre as Mães que perderam seus filhos nas mãos de Policiais despreparados [...]".

Es un colectivo que se estructura en torno a la energía de madres que han vivido algo común: la experiencia de la pérdida. Una experiencia que conecta el sentirse vacías, la angostura/presión de la angustia y el echar de menos. Justamente en el polo opuesto, la confianza ensancha, abre, conecta, Ilena y hace presente. Las madres compañeras de angustia posibilitan hacer el duelo y retomar la senda personal construyendo un colectivo. Ellas dicen:

Mães vamos juntas lutar por justiça, pelas mortes dos nossos filhos, sabemos que a segurança pública (policiais) já mataram muitos e infelizmente vão continuar matando [...].

No Brasil não há pena de morte (TEM SIM, POLICIAIS FAZEM ISSO!) Não estou e jamais vou apoiar a criminalidade, é mais do que certo ERRO? tem que pagar pelo seu erro sim, mas pagar na cadeia e não com a vida. Para isso existe a cadeia!

Infelizmente mãezinhas nada vai trazer nossos filhos de volta. A luta por justiça é grande? sim, é muito lenta? sim. Mas vamos se unir, não vamos deixar que nossos filhos sejam apenas mais um número nas estatísticas [...].

${ }^{6}$ Fórum Brasileiro de Segurança Pública Rua Amália de Noronha, 151 · Conj. 405 Pinheiros, São Paulo - SP · Brasil www.forumseguranca.org.br. 
Vamos juntas lutar para que outras mães não passe pelo que nós estamos passando, não vamos deixar que outras mães sinta essa dor, esse vazio, essa saudade [...]. Que outras mães perca a vontade de viver, não vamos deixar outras mães ficarem como nós, uma morta viva lutando todos os dias para continuar sobrevivendo [...].

Vamos mães se unir não tenha medo, não se cale, a união faz a força [...].

VAMOS JUNTAS LUTAR POR JUSTIÇA!!!" (Mães em Luto da Zona Leste, Facebook).

Las madres se dan y dan confianza en la unión. La confianza contradice el vacío y la "saudade". El punto de partida de la "fuerza" es el dolor, la soledad y el vacío. Estados todos de vivencias de la pérdida que es identificada, descripta y explicada en tanto causada por la policía. Es el aparato represivo del estado orientado a suprimir a lo abyecto que "justifica" la muerte de niños y adolescentes bajo la cobertura de peligros, criminales y drogadictos. Las madres confían en ese horizonte compartido de compresión del fenómeno dado que la otra vive/vivencia lo mismo. El rasgo cognitivo de las emociones que todas ellas experimentan es uno de los pilares del puente que constituye su mutua confianza.

El Ilorar causado por esas vivencias comunes potencia el esperar de la otra comportamientos similares y el compromiso con las acciones colectivas. Un rasgo del dolor común de estas madres es la tristeza por la vida en plenitud de sus hijos. Ellos/ellas "tenían una vida por delante" y con su muerte no solo se trunca su vida sino la de su madre y familia.

\section{AUPAPREM (Uruguay)}

En la información de su Facebook, se puede leer un escueto "Aupaprem es una asociación de padres y familiares de bebés prematuros". Esta Red es un excelente ejemplo de las energías del amor filial como vertebradora de práctica colectiva.

Este colectivo de padres que han tenido hijos prematuros se une ante la incertidumbre: la confianza es la contracara de lo incierto, la confianza da, produce y reproduce certezas. Cuando una familia, y especialmente 
una mamá, debe enfrentar la venida anticipada de un niño lo que se rompe es justamente la previsibilidad del entorno: todo está preparado para nueve meses no para antes. Confiar implica un manejo de la ruptura de la reproducción del mundo en base a los lazos de reconocimiento de prácticas, sentidos y vivencias.

Este grupo de padres, cuyas prácticas parecen estar muy distanciadas de otras más políticas o de compromiso social, deja en evidencia el carácter multipolar de la energía del amor filial: el solo tener que cuidar a las hijas e hijos se transforma en un síntoma, en el señalamiento de una ausencia y la producción de un mensaje. AUPA indica claramente cómo los sistemas de educación no dan una respuesta adecuada y los sistemas de salud (estatales o privados) por su inexistencia o por su costo hacen de esta experiencia una de alto riesgo, y en este sentido marcan un síntoma de la estructuración social. Por otro lado, estos padres aunándose dejan en evidencia las ausencias de una estructura que "olvida" lo interpersonal como factor clave del cuidado y la reproducción de la especie, vía ineficiencia o mercantilización. El cuidado no es ya algo reservado a la mujer, no solamente del "interesado", ni recae en los más débiles, el respaldo colectivo abre la puerta para un cuidado común.

Lo que sigue son tres recomendaciones del perfil en Facebook que dejan ver las tramas del contenido de este colectivo armado desde el cuidar y cuidarse:

"La contención apropiada en el momento justo de parte de personas que pasaron por una experiencia similar es muy necesaria. Aupaprem está comprometida con la vida. iGracias por acompañarnos en cada pequeño gran paso!"

"Recomiendo Aupaprem por surgir ante la situación de una madre que hace 15 años atrás vivenció con el menor de sus hijos el tema de la prematurez, y a partir de allí su vida la volcó en ayudar y motivar a otros padres también prematuros a brindarle diferentes ayudas en el periodo de internación y a partir del alta, caminos que ella misma recorrió que bastante difícil le fue descubrir para apoyar a su hijo que a través de Aupaprem pudo trasmitir la generosidad de compartir, y ese fué solo el comienzo. Andrea Milgron logra reunir cada año profesionales calificados para guiar a los padres prematuros 
al alta, en talleres o jornadas en pro- de la concientización de la prematurez. Ha posibilitado que madres más necesitadas reciban ropa u otros objetos para su hijo/a. Además de motivar y publicitar cada emprendimiento que surge como iniciativa laboral de las madres que viven la realidad. Convoca padres prematuros que se hacen visible y representados a nivel político exigiendo leyes necesarias para que existan para ésta cada vez mayor población de niños y madres que deben estar más tiempo al cuidado de su hijo sin que implique perder su trabajo.

AUPAPREM hoy está integrado por muchos padres dando de si apoyo y contención, así como brindando información y materiales instrumentales que reciben de otros países y empresas que donan a beneficio de esta Organización.

Personalmente he tenido la oportunidad de participar de los encuentros y se logra un auténtico clima para el intercambio, familias necesitadas de compartir su experiencia como padres, contando las peripecias vividas y los logros alcanzados que da gusto aceptar cada ocasión dónde Andrea me invita a formar parte.

Si hay algo que brinda esta Asociación es la apertura y bienvenida a todos los padres con sus hijos prematuros."

\section{Red de madres buscando a sus hijos (México)}

La actual administración de México muy recientemente ha aceptado, a través de la palabra del subsecretario de Derechos Humanos, Alejandro Encinas, y de su presidente, que el número de desaparecidos en el país es de 40.000, 26.000 cuerpos sin identificar y 1.100 fosas comunes. ${ }^{7}$ Más allá de los acuerdos o no con la cantidad, lo que ello implica es la aceptación institucional de una problemática que trae aparejado un profundo dolor y tristeza. La Red que aquí mencionamos es solo una de las organizaciones y colectivos dedicadas a esta problemática.

Las madres de la Red en su blog dicen claramente:

Somos una red de madres que se acompañan en la búsqueda de sus hijos desaparecidos. iTú puedes ayudarnos!

${ }^{7}$ https://www.lapoliticaonline.com/nota/117534-lopez-obrador-confirmo-que-en-mexicohay-40-mil-desaparecidos/ 
Es un colectivo que se imbrica entre el acompañarse, la búsqueda y la ayuda. Lo primero que se ve es el rostro de una mujer mirando, expectante sobre la que se sobre escribe la leyenda citada arriba. Más abajo la atmosfera triste se transforma en pragmático consejo "¿Qué hacer frente a la desaparición de alguien? Nadie nace y le enseñan cómo comportarse frente a una desaparición y estas madres van directo a ese vacío: te acompañan".

Un desaparecido implica una silla vacía, puntos suspensivos entre paréntesis, un cumpleaños sin cumpleañero, significa que vivas se las llevaron. El desaparecido es una ausencia estructurante de la permanente falta de alguien.

La Red está constituida por madres que buscan, que están en tensión entre lo que aún no confirman que han perdido y los dolores del sentir la pérdida. Este grupo de madres que nace de la búsqueda de Lety, mujer que perdiera y supiera de la muerte de su hija luego de dos años de búsqueda, y que sabe qué significa la angustia del buscar. Ellas mismas se describen del siguiente modo:

\section{¿QUIÉNES SOMOS?}

Nuestra organización nace de la solidaridad.

Somos un grupo de familias que han tenido la desdicha de vivir la desaparición de un ser querido. Nuestra organización nace de la empatía, la solidaridad y la entrega de Lety, quien, durante la búsqueda de su hija, se dio cuenta que otras madres enfrentaban la misma indiferencia e insensibilidad de parte de las autoridades. Por ello, decidió unirse con ellas para acompañarse y hacerse fuertes unas a las otras: juntas comenzaron a exigir al Ministerio Público y a la Procuraduría de Toluca, así como a difundir sus casos y denunciar la falta de compromiso de las autoridades a través de los medios de comunicación. Desde entonces, nuestra organización ha crecido: fuimos parte del Movimiento por la Paz con Justicia y Dignidad y ahora estamos trabajando en diferentes estados de la República.

La claridad es meridiana, la red nace de la solidaridad entre familias que evidencian la identificación de la empatía y la entrega de una mamá como acicate de la organización. Son justamente las conexiones entre amor filial y confianza las que, según estas familias, las empujan a buscar y 
acompañarse. La percepción compartida es la indiferencia e insensibilidad de las autoridades, lo que las une y reúne en la denuncia.

\section{Familiares y Amigos de Víctimas y Heridos de la Tragedia de Once 22/2 (Argentina)}

Esta asociación de familiares y amigos se constituyó en base a un accidente ferroviario que claramente visibilizó la desatención y peligro implicado en las corrupciones tramadas en y a partir de la infraestructura y obra pública. La corrupción mata. La desatención destruye vidas. La indiferencia gubernamental es un delito. Estas prácticas intersticiales que devienen acciones colectivas muestran cómo la unión, fuerza y la persistencia en organizarse en un "más acá" de movimientos sociales y partidos políticos es lo que les da consistencia y legitimidad.

En el primer lustro del presente siglo es posible identificar en Argentina un conjunto de prácticas intersticiales que denuncian y a la vez desmienten que lo único que exista en la economía política de la moral sea impunidad, desatención y corrupción. Este es un grupo de padres, madres, hermanos, parientes, solos frente al dolor y al Estado, frente a la pérdida y el poder. Un día antes, poco sabían estas personas del dolor de la muerte, del trato con abogados y/o destrato de un Estado abandónico. Para ellos el punto de giro de sus vidas fue la muerte de sus seres queridos.

En su último documento público, extenso y comprometido, denuncian:

Siete años han pasado ya desde la mañana que dividió nuestra vida en dos. Una mañana igual a esta, se aplastaba la vida de 52 inocentes en el tren chapa 16. El país miraba perplejo, sin poder creer lo que los televisores, radios, diarios, y páginas de internet reproducían. Mientras, nosotros recorríamos estos andenes y el hall de la estación. Buscábamos los ojos de nuestros familiares para cruzarlos con los nuestros, sus brazos estirándose para abrazarnos, o al menos un dato para ir a su encuentro. Hospitales, comisarías, móviles de los medios de comunicación ¿Dónde estás? Cuantas veces repetimos esa pregunta al aire, hundidos en la desesperación de manera cada vez más profunda. En las frías morgues de la Chacarita y la calle Viamonte encontramos la más terrible, injusta e inexplicable de las respuestas. Con solo cerrar los ojos, cualquiera de nosotros vuelve a ese momento, escucha una y otra vez los ruidos de las sirenas rebotando en nuestra cabeza. Y después, el silencio (énfasis añadido). 
En un punto que cruza y articula a todos los colectivos que analizamos, aquí aparece la búsqueda, la necesidad del encontrar y el encuentro y el abrazo, este gesto cuerpo/emoción que familiares y amigos de toda Latinoamérica repiten como práctica corporal fundante, el abrazar.

Todos estos años de gente, dijo el gran Spinetta. Eso son estos siete largos años. Años de gente común, eso somos y también lo es cada persona que nos acompañó en la búsqueda de justicia sin conocer renunciamientos ni entregas, con una convicción que se fue fortaleciendo más y más cada día (énfasis añadido).

La búsqueda es fruto de un creer, de una convicción y de un acompañarse: la confianza que nace en las tramas del amor filial en tanto energía colectiva. Lo común que se basa en la no traición, en la capacidad de todos los comunes que ponen en común la fidelidad de la confianza.

Un dicho que desborda sabiduría dice que lo prometido es deuda. Porque además no hay deuda mayor que la de escuchar las alertas y garantizar que nunca más la sangre de inocentes manche las vías de este país. Estaremos atentos a que las obras prometidas se cumplan (énfasis añadido).

La expectativa de cumplir lo prometido es ese resorte básico de toda confianza y en dicho esperar con la seguridad que se cumplirá radica la motivación radical de un amor filial que se ha reproducido en prácticas del sentir.

Por eso, es hora que nosotros y tantas otras víctimas de la corrupción, podamos sentir que los poderes de Estado piensan en nosotros, antes que en cualquier otra cosa. Porque no hay propiedad privada ni pública más importante que la vida misma. [...] Huérfanos, viudas, viudos, padres y hermanos que hemos enterrado hijos, hermanos, hermanas y cientos de heridos nos lo merecemos más que nadie y antes que cualquier contexto electoral. [...] Y nadie puede decir que no hemos sido pacientes. [...] Elegimos el camino más difícil, sabiendo que encontraríamos muchísimos escollos en el camino. [...] Al dolor le opusimos fortaleza, al descreimiento en la Justicia le enfrentamos nuestra confianza y a la desazón una constancia de la que nadie puede dudar (énfasis añadido). 
El resorte: el amor filial; el vehículo: la confianza; y el resultado: la búsqueda de la justicia; el proceso dialéctico de la práctica colectiva se describe perfectamente.

Nuestro corazón podrá sentir cada vez más el golpe de las ausencias, pero nos mantendremos de pie, para volver siempre al grito que es uno, que nos une y que no dejará de retumbar en estos andenes mientras nos quede vida para hacerlo. JUSTICIA PARA LOS MUERTOS Y HERIDOS DE ONCE.

Si la corrupción mata, el amor mueve y la confianza reconstruye lazos, espacios y cuerpos/emociones.

\section{\#nosduelen56 (Guatemala)}

Guatemala nos enfrenta a una de las redes de conflicto más extendidas en el mundo contemporáneo: el feminicidio. En el contexto de los nuevos ciclos de protestas de los últimos cinco años, una práctica que ha asolado a la sociedad guatemalteca desde hace algún tiempo, tal como el asesinato de mujeres, también es visible en y a través de diversas acciones colectivas. Con el fin de mostrar la energía de amor filial, lo que sucede en Guatemala tiene tres características muy interesantes: a) no hay grupos más o menos permanentes, b) son las protestas que utilizan recursos expresivos como las acciones colectivas ya mencionadas en los últimos años, y c) especialmente el "Nos duelen 56" muestra claramente que en muchas ocasiones el amor filial como fuente de acción colectiva se nutre y atravesado por otros grupos y energías.

Guatemala es uno de los países con más femicidios y también la tierra del compromiso de miles de mujeres con los derechos humanos en general y los de las mujeres en particular. Durante los últimos años, han convivido en este país corrupción, protestas sociales, enjuiciamiento de presidente y desatención, muerte y abuso de niñas y mujeres. El colectivo que aquí analizamos pertenece a las modalidades de prácticas intersticiales basadas en el amor filial originadas en la motivación desde diversas organizaciones sociales. Las madres aquí son convocadas por los colectivos militantes $y$, desde ese lugar, se inicia la visibilidad de la tragedia y el pilar de la 
refundación de la confianza. El amor filial es convocado para tramar la confianza en la denuncia, pero también para inspirar la fiabilidad de las madres y familiares.

A raíz del incendio registrado el 8 de marzo de 2017 en un hogar en el que murieron 41 niñas, 'Prensa Comunitaria', con el apoyo del 'Colectivo 8 Tijax', propuso la iniciativa de memoria \# acción global \#NosDuelen56 ${ }^{8}$, dos meses después de la muerte de las niñas en una casa del Estado. Gracias a la iniciativa de grupos feministas y colectivos sociales, el grupo de mujeres ha reanudado acciones a favor de las niñas, la realización de actividades junto con algunas madres de las niñas afectadas. Sin embargo, no existe un grupo específico que conduzca las acciones. En la conmemoración del 7 de mayo de 2018, es posible leer y ver en uno de sus muros militantes:

\#NosDuelen56 es un grito por la justicia desde el arte, el periodismo, el medioactivismo y los feminismos. Fue impulsado el 15 de mayo por dos medios de comunicación alternativos Prensa Comunitaria de Guatemala y Desinformémonos en México y otros 60 medios digitales y 40 organizaciones y colectivos del mundo que se unieron a una sola voz. [...] \#NosDuelen56 se suma a las acciones y luchas por exigir \#NiUnaMenos [...]. ${ }^{9}$

Como es fácil advertir, el "nos duelen" es evidencia de la acción performativa del dolor de otro - se siente el dolor en carne propia y se expresa en y desde tres caminos concurrentes: el periodismo alternativo, la militancia en los medios y el feminismo. Aquí no hay familiares sino personas que se "sienten" en consonancia con el dolor de las jóvenes, pero que convocan y reúnen a madres, familiares y mujeres en general. La percepción compartida de un estado de cosas genera la confianza de estar juntos en función de algo común:

Es un ejercicio de memoria colectiva y de dignificación por las 56 niñas que fueron encerradas y quemadas en un hogar estatal en Guatemala el pasado 8 de marzo del presente año [2017]. De ellas, 41 murieron como resultado de este crimen femicida y 15 están con heridas de gravedad.

${ }^{8} \mathrm{https}: / /$ www.facebook.com/NosDuelen56/

${ }^{9} \mathrm{https}: / /$ medium.com/nos-faltan-56/nos-duelen-56-66c6984d8f44 
Convocar a las madres y facilitar el acto de habla performativo que implica narrar el dolor permite hacerlo público/colectivo y esto se convierte en la plataforma que redefine al dolor en falta y, con esta, el desplazamiento de lo local a lo global.

El arte es la fuerza motriz que pone rostros y colores al duelo por las 41 niñas que murieron masacradas. A través de esta acción manifestamos nuestra intención porque el mundo las recuerde. Este es el resultado de la contribución de 58 artistas de México, Argentina, Francia, Italia, España y Guatemala. \#NosDuelen56 es nuestra contribución por las niñas, contra la impunidad y el olvido.

El movimiento \# niunamenos, colectivos de artistas y medios de comunicación alternativos hacen visibles el dolor de las madres y familiares, pero también el de la sociedad toda que lo comparte y quiere "decir algo al respecto".

\section{Fundación Emilia (Chile)}

Este colectivo es un ejemplo de cómo el amor filial deviene motivación de institucionalización - en este caso, la conformación de una fundación dedicada a la prevención de accidentes de tránsito. La muerte de una hija y las disputas con las sociabilidades aceptada y aceptable marcan un punto de inflexión en la vida de una madre.

Este punto de giro condensa y estructura una energía dirigida a la institucionalización de la confianza. Tras el diagnóstico de que esas muertes se pueden evitar en y a través de políticas activas del Estado, educación del ciudadano y promoción por los mass media, se organiza una fundación dispuesta a señalar y suturar las faltas del Estado. El amor filial, al canalizarse en la institucionalidad de una "fundación", logra que otros/otras compartan no solo el diagnóstico sino también las expectativas de transformar lo dado. Esta fundación se orienta a proponer, hacer votar y obtener una ley que, tomando el nombre de la niña, es un vehículo privilegiado para producir confianza en lo institucional.

Paralelamente, la Fundación organiza un conjunto de vídeos cuya finalidad es compartir la confianza de acompañarse y estar al lado de 
los "que-tienen-que-pasar por la pérdida". En estos vídeos se cristaliza la importancia de que otros sepan de las vivencias experimentadas. Esta organización también prepara "campañas" de concientización, maratones, dramatizaciones etc. que procuran socializar comportamientos adecuados, que evitan/reducen los riesgos. En su Facebook se puede leer:

Qué hacemos?

Misión

Propiciamos una cultura de responsabilidad social vial en la que nunca más tengamos que lamentar la pérdida de vidas producto de siniestros y delitos de tránsito.

Visión

Promovemos una cultura vial responsable y acompañamos a las víctimas de siniestros y delitos viales.

Objetivos

1 Acompañar a las víctimas y sus entornos familiares de afectados por delitos vinculados a la Ley Emilia, buscando entregar un apoyo: personal, psicológico y jurídico.

2 Desarrollar campañas de sensibilización y educación, que permitan fomentar una ciudadanía más consciente y responsable de su comportamiento en la plaza pública.

3 Desarrollar investigación, la cual permita plantear políticas públicas, gestión ciudadana y cambios legislativos, instancias vinculadas con la formación y educación del comportamiento en la plaza pública.

Como en muchos otros colectivos, lo que empieza como amor filial se va configurando en el mandato de sensibilizar a la sociedad - no es solo tomar conciencia en términos cognitivos sino y fundamentalmente inscribirse en otra práctica del sentir, construyendo una política de la sensibilidad.

Estas seis experiencias nos indican al menos tres constantes: a) cómo la vivencia de un "punto de giro" modifica la vida de las personas afectadas, b) cómo el amor filial motiva/genera diversas modalidades de prácticas colectivas, y c) cómo emergen desde estas prácticas intersticiales 
"redefiniciones" de la confianza como contrapunto a la economía política de la verdad vigente.

En el cuadro que sigue se puede observar algunos rasgos centrales de las prácticas colectivas a las que se ha hecho referencia.

\section{Cuadro 1- Emociones, disputas y confianza.}

\begin{tabular}{|c|c|c|c|c|}
\hline $\begin{array}{c}\text { País } \\
2010 \text { a } 2017\end{array}$ & Colectivo & $\begin{array}{c}\text { Matriz } \\
\text { conflictual }\end{array}$ & Emociones & Confianza \\
\hline $\begin{array}{l}\text { BRASIL } \\
\text { https://www. } \\
\text { facebook.com/ } \\
\text { MaesEmLutodaZonaLeste/ }\end{array}$ & $\begin{array}{l}\text { Mães em } \\
\text { Luto da Zona } \\
\text { Leste. }\end{array}$ & $\begin{array}{l}\text { Justicia; } \\
\text { violencia } \\
\text { policial; } \\
\text { derechos } \\
\text { humanos. }\end{array}$ & $\begin{array}{l}\text { Sentirse } \\
\text { vacías, la } \\
\text { angostura/ } \\
\text { presión de } \\
\text { la angustia y } \\
\text { el echar de } \\
\text { menos. }\end{array}$ & $\begin{array}{l}\text { Ensanchar, } \\
\text { abrir, conectar, } \\
\text { llenar y hacer } \\
\text { presente. }\end{array}$ \\
\hline $\begin{array}{l}\text { URUGUAY } \\
\text { https://www.facebook. } \\
\text { com/aupaprem/ }\end{array}$ & $\begin{array}{l}\text { AUPAPREM } \\
\text { Asociación } \\
\text { Uruguaya } \\
\text { de Padres } \\
\text { con Hijos } \\
\text { Prematuros. }\end{array}$ & $\begin{array}{l}\text { Calidad de } \\
\text { vida de sus } \\
\text { hijos, nietos } \\
\text { y familiares. }\end{array}$ & $\begin{array}{l}\text { Miedo, } \\
\text { incertidumbre. }\end{array}$ & $\begin{array}{l}\text { Compartir, } \\
\text { generosidad y } \\
\text { sentirse parte. }\end{array}$ \\
\hline $\begin{array}{l}\text { MEXICO } \\
\text { http://reddemadres.org/ }\end{array}$ & \begin{tabular}{|l} 
Red de \\
madres \\
buscando a \\
sus hijos.
\end{tabular} & $\begin{array}{l}\text { Vida, } \\
\text { derechos } \\
\text { humanos, } \\
\text { desaparición, } \\
\text { muerte. }\end{array}$ & $\begin{array}{l}\text { Dolor, tristeza } \\
\text { y desdicha. }\end{array}$ & $\begin{array}{l}\text { Acompañar, } \\
\text { ayudar, } \\
\text { conectar. }\end{array}$ \\
\hline $\begin{array}{l}\text { ARGENTINA } \\
\text { https://www.facebook. } \\
\text { com/TRAGEDIAONCE/ }\end{array}$ & $\begin{array}{l}\text { Familiares y } \\
\text { Amigos de } \\
\text { Víctimas y } \\
\text { Heridos de la } \\
\text { Tragedia de } \\
\text { Once } 22 / 2 \text {. }\end{array}$ & $\begin{array}{l}\text { Corrupción, } \\
\text { desamparo. }\end{array}$ & $\begin{array}{l}\text { Impotencia, } \\
\text { dolor, bronca. }\end{array}$ & $\begin{array}{l}\text { Encontrar(se), } \\
\text { persistir, } \\
\text { fidelidad. }\end{array}$ \\
\hline $\begin{array}{l}\text { GUATEMALA } \\
\text { https://www.facebook. } \\
\text { com/NosDuelen56/ }\end{array}$ & $\begin{array}{l}\text { Nos duelen } \\
56 .\end{array}$ & $\begin{array}{l}\text { Violencia } \\
\text { contra la } \\
\text { Mujer, } \\
\text { violencia } \\
\text { contra } \\
\text { la niñez, } \\
\text { femicidio, } \\
\text { justicia. }\end{array}$ & $\begin{array}{l}\text { Dolor, } \\
\text { Tristeza, } \\
\text { Enojo. }\end{array}$ & $\begin{array}{l}\text { Verdad, ayuda, } \\
\text { recuerdo. }\end{array}$ \\
\hline $\begin{array}{l}\text { CHILE } \\
\text { http://www. } \\
\text { fundacionemilia.cl/ }\end{array}$ & $\begin{array}{l}\text { Fundación } \\
\text { Emilia. }\end{array}$ & $\begin{array}{l}\text { Imprudencia, } \\
\text { alcoholismo, } \\
\text { muerte, } \\
\text { violencia } \\
\text { social. }\end{array}$ & $\begin{array}{l}\text { Dolor, } \\
\text { tristeza, } \\
\text { impotencia. }\end{array}$ & $\begin{array}{l}\text { Apoyo, } \\
\text { reconocimiento } \\
\text { y aliento. }\end{array}$ \\
\hline
\end{tabular}




\section{A modo de cierre}

El amor filial configura así la posibilidad de establecer un mapeo de prácticas intersticiales que, en el contexto de los "puntos de giro" que implican para los participantes de las acciones colectivas analizadas, dejan ver como son los quiebres de la economía política de la moral y sus pretensiones de totalidad.

En la sistematización realizada en el cuadro de arriba es fácil advertir que: la emoción común entre las diversas experiencias es el dolor, que el rasgo compartido de la confianza es el conectar(se) y que la matriz conflictual más repetida es la conectada con diversos tipos de violencias.

Si pensamos, al menos en las experiencias aquí reseñadas, que la vida colectiva de estas prácticas basadas en el amor filial nos indica la conexión/tensión entre matriz conflictual, emociones prevalentes y rasgo de la confianza que se potencia, es posible visualizar cómo los puntos de giro que experimentan las personas que constituyen estas prácticas de amor filial se inscriben en alguna red de conflicto y en alguna matriz conflictual. Si bien es posible resumir en la violencia las experiencias de cambio que han vivido las personas que integran los colectivos analizados, es menester precisar su referencia a la brutalidad policial, a la ausencia estatal y del mercado en la calidad de vida, en la desaparición y trata de personas, en la corrupción, en la violencia de género y femicidio y en la imprudencia e irresponsabilidad. A su vez, estas redes de conflictos se inscriben en las ausencias del Estado y del mercado, en las fallas institucionales y en el desamparo. Las matrices conflictuales específicas disparan la vivencia de emociones particulares.

Madres, padres, hermanos, familiares y amigos experimentan y comparten un conjunto de emociones similares entre las que se destaca, como ya se ha dicho, el dolor: pérdida, herida, falta, vivida como profunda y repetitiva. Angustia, miedo, incertidumbre, desdicha, impotencia, bronca, enojo y tristeza, son las emociones más referidas que advienen como efecto de lo que se ha perdido.

Si bien aquí no nos podemos detener en una exposición más detallada, si hay una emoción que enfrentan (junto al dolor) estas prácticas colectivas 
es el miedo ${ }^{10}$, asociado siempre con la pérdida y la impotencia, con la imposibilidad y la falta. Estas prácticas intersticiales, por esta vía, se convierten en prácticas contrafantasmáticas que desmienten el régimen de verdad de la economía política de la verdad.

Es en este marco que el amor filial se comunica como una emoción (energía) que transforma la realidad (sensu, Sartre), corre el eje desde el dolor y el sufrimiento y lo convierte en oportunidad de cambio y confianza.

Es en este punto que el recorrido helicoidal de la energía del amor filial redefine y provoca la confianza desde la cotidianidad de como las personas viven la vida en y a través de esos colectivos: la vivencias se ensanchan, abren, aparece el compartir, ayudar, el hacerse presente, el acompañar. Son experiencias del persistir, de la fidelidad, son formas autónomas de hacer colectivo. La confianza vuelve en tanto encuentro y encontrarse. Las personas persisten en el amor y logran la confianza de encontrar a otros y a sí mismos en una lucha desigual contra el dolor planteado desde lo individual y fragmentario. El otro está ahí para ser alentado, ayudado, esperado $-\mathrm{y}$ todos se transforman en ese otro.

Adrián Scribano es Investigador Principal de CONICET en el Instituto de Investigaciones Gino Germani, Facultad de Ciencias Sociales, Universidad de Buenos Aires.

$\equiv$ adrianscribano@gmail.com.

${ }^{10}$ Para una mirada sobre miedo y su "lugar" en la sociedad, ver Koury, Zamboni e Brito (2013), Koury e Barbosa (2015; 2016). 


\section{Referencias}

1. CÂMARA, Hélder. Spiral of violence. Londres: Sheed and Ward, 1971.

2. DE COCK, Evi et al. Continuous feelings of love? The parental bond from pregnancy to toddlerhood. Journal of Family Psychology, v. 30, n. 1, p. 125-134, 2016. dol: 10.1037/fam0000138

3. DE SENA, Angelica; LISDERO, Pedro. Etnografía virtual: aportes para su discusión y diseño. In: DE SENA, Angelica. Caminos cualitativos: aportes para la investigación en Ciencias Sociales. Buenos Aires: CICCUS- Imago Mundi, 2015. p. 71-100.

4. KÁLMÁN, György C. Turning points in research: systems and theory. Corela [En línea], HS-19, 2016. doi: 10.4000/corela.4536

5. KOURY, Mauro G.; ZAMBONI, Marcela; BRITO, Simone. Como se articulam vergonha e quebra de confiança na justificação da ação moral. Dilemas: Revista de Estudos de Conflito e Controle Social, v. 6, n. 2, p. 251-268, 2013.

6. KOURY, Mauro G.; BARBOSA, Raoni. Pânico, disputas morais e vergonhadesgraça em um bairro periférico da cidade de João Pessoa - PB. Anales de XI RAM, Montevidéu, 2015.

7. KOURY, Mauro G.; BARBOSA, Raoni. Ação violenta entre amigos. Reflexão etnográfica sobre processos de percepções e justificações morais e emocionais de condutas. Anais do 40o Encontro Anual da ANPOCS, ST 34. Caxambu, ANPOCS, 2016.

8. LEVINAS, Emmanuel. Totality and infinity: an essay on exteriority. La Haya: Martin Nijhoff Publishers, 1979.

9. MARCEL, Gabriel. Being and having. Glasgow: The University Press, 1949.

10. MOUNIER, Emmanuel. Personalism. Londres: Routledge \& Kegan Paul, 1962.

11. MOSQUERA, Manuel A. De la etnografía antropológica a la etnografía virtual. Fermentum, v. 18, n. 53, p. 532-549, 2008.

12. PULCINI, Elena. What emotions motivate care? Emotion Review, v. 9, n. 1, p. 64-71, 2017. doi: 10.1177/1754073915615429

13. PINK, Sarah et al. Introduction. In: PINK, Sarah et al. Digital ethnography: principles and practice. Londres: Sage, 2016.

14. SCRIBANO, Adrián. Una aproximación conceptual a la moral del disfrute: normalización, consumo y espectáculo. Revista Brasileira de Sociologia da Emoção, v. 12, n. 36, p.738-751, 2013a.

15. SCRIBANO, Adrián. La religión neo-colonial como la forma actual de la economía política de la moral. Revista Prácticas y Discursos, v. 1, n. 2, p.1-20, 2013b. doi: 10.30972/dpd.22716

16. SCRIBANO, Adrián. El don: entre las prácticas instersticiales y el solidarismo. Sociologias, v. 16, n. 36, p.74-103, 2014. doi: 10.1590/15174522-016003605 
17. SCRIBANO, Adrián. Consumo, disfrute inmediato y desechos: hacia una caracterización metonímica de unas sociedades depredatorias. In: VERGARA, Gabriela (Comp.) Recuperadores, residuos y mediaciones. Análisis desde los interiores de la cotidianeidad, la gestión y la estructuración social. Buenos Aires: Estudios Sociológicos Editora, 2015a. p.135-154.

18. SCRIBANO, Adrián. iDisfrútalo! Una aproximación a la economía política de la moral desde el consumo. Buenos Aires: Elaleph.com, 2015b.

19. SCRIBANO, Adrián. Normalization, enjoyment and bodies/emotions: Argentine sensibilities. Nueva York: Nova Science Publishers, 2017.

20. SKÅGEBY, Jörgen. Online ethnographic methods: towards a qualitative understanding of virtual community practices. In: DANIEL, Ben K. (Ed.). Handbook of research on methods and techniques for studying virtual communities: paradigms and phenomena. Hershey, EUA: IGI Global, 2010.

21. TURABIAN, Jose L. (2017) Women and transitions: the theory of turning points. Journal of Women's Health Care, v. 6, n. 5, 1000e130, 2017. doi: 10.4172/2167-0420.1000e130

22. WINKIN, Yves. Erving Goffman: the moments and their men. Barcelona: Paidós, 1991. 
